\title{
Accidental displacement of impacted maxillarythird molar: A case report
}

Zuhaib $\mathbf{M}^{1}$, Sharma $\mathbf{P}^{2}$, Doley $\mathbf{B}^{3}$

${ }^{1}$ Mohammed Zuhaib-BDS,MDS ,Observer in the Dept of Oral Oncology, Kidwai Memorial Institute of Oncology, Bangalore, ${ }^{2}$ Pradeep Sharma,BDS, MDS,Senior Lecturer in Dept of Oral \& Maxillofacial Surgery, I.T.S Dental College, Ghaziabad, ${ }^{3}$ Bonita Doley, BDS, MDS, Private practitioner.

Address for correspondence: Dr Mohammed Zuhaib, Email: dr.mohammedzuhaib@gmail.com

\begin{abstract}
An unusual case of an impacted right maxillary third molar that was accidentally displaced into the maxillary sinus during exodontia was surgically retrieved almost 2 months later is described. The tooth was removed under Local anesthesia, after maxillary sinus exposure through Caldwell-Luc approach. Postoperative recovery was uneventful. A month after the retrieval surgery, the maxillary sinus was fully healed and the patient did not present with any complaint.
\end{abstract}

Keywords: Third Molar, Intraoperative Complications, Accidental Displacement.

\section{Introduction}

Removal of impacted maxillary third molars is a common surgical procedure performed by oral surgeons and dentists alike. As expected with any surgical intervention, accidents may occur during exodontia, such as tooth displacement into the maxillary sinus. Although this type of accident has often been mentioned in oral surgery textbooks, very few cases have been reported in the literature [1,2]. The presence of a tooth inside the sinus may lead to complications such as infection, and thus its surgical removal is strongly recommended [2]. This report describes an unusual case of impacted maxillary third molar that was accidentally displaced into the maxillary sinus during extraction, where it remained for almost two years.

\section{Case Report}

An eighteen-year-old male patient was referred to the Dental office, with the chief complaint of pain in the right infra-orbital area and bad taste on swallowing since two months. The patient informed that a general dentist surgically extracted the right maxillary third molar 3 weeks before. The procedure was described as being complicated, but the professional did not inform the patient of any intraoperative accident. Intraoral

\footnotetext{
Manuscript received: $4^{\text {th }}$ July 2015

Reviewed: $14^{\text {th }}$ July 2015

Author Corrected: $27^{\text {th }}$ July 2015

Accepted for Publication: $13^{\text {th }}$ Aug 2015
}

clinical examination revealed only absence of the third molars. A panoramic radiograph suggested the presence of a tooth inside the right maxillary sinus (Fig. 1). The panoramic radiograph taken after extraction of the third molars was requested to the patient and helped to confirm the removal of tooth displacement (Fig. 2). Frontal and transverse computed tomography (CT)scans (Figs. 3-5) were taken to determine the precise position of the tooth in a three-dimensional view. These images showed that the tooth was located approximately in the center of the maxillary sinus. In addition, secretion was observed in the right maxillary, frontal and etmoidal sinuses. Under Local anesthesia, the maxillary sinus was exposed through Caldwell-Luc approach and showed a large quantity of purulent secretion. The tooth was removed only with the help of curved forceps (Fig. 7). The sinus was cleaned by intensive irrigation with saline and a meatotomy was performed to enlarge the meatalostium. The wound was closed with polyglactin 910.Diclofinac sodium $(50 \mathrm{mg}+$ Paracetamol $375 \mathrm{mg})$ and clindamicine $(1800 \mathrm{mg} / \mathrm{day})$ were prescribe. Postoperative recovery was uneventful. After 6 months, CT scans showed good healing of the maxillary sinuses (Fig. 8), in spite of bilateral enlargement of the mucosa, and the patient did not present any complaint. 


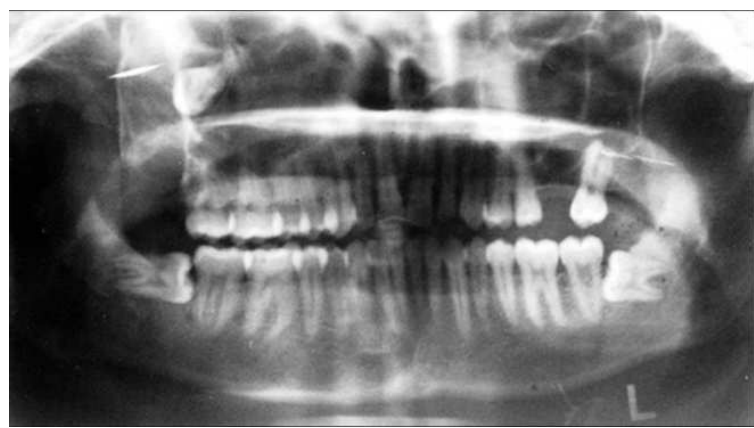

Figure 1: Panoramic radiograph taken at the patient arrival, the presence of a tooth into the right maxillary sinus

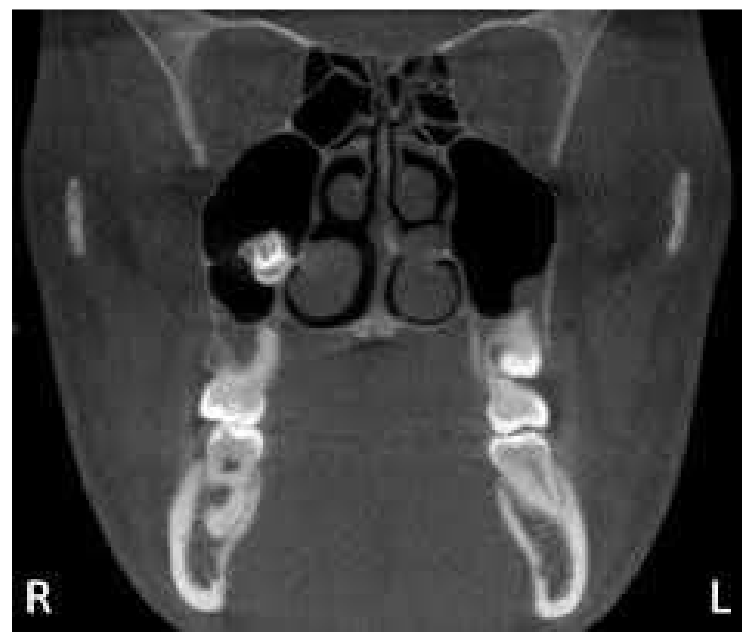

Figure 3: Frontal CT scan showing the vertical position of the tooth posterior inside the maxillary sinus and large amount of secretion in the maxillary sinus and the etmoidal cells

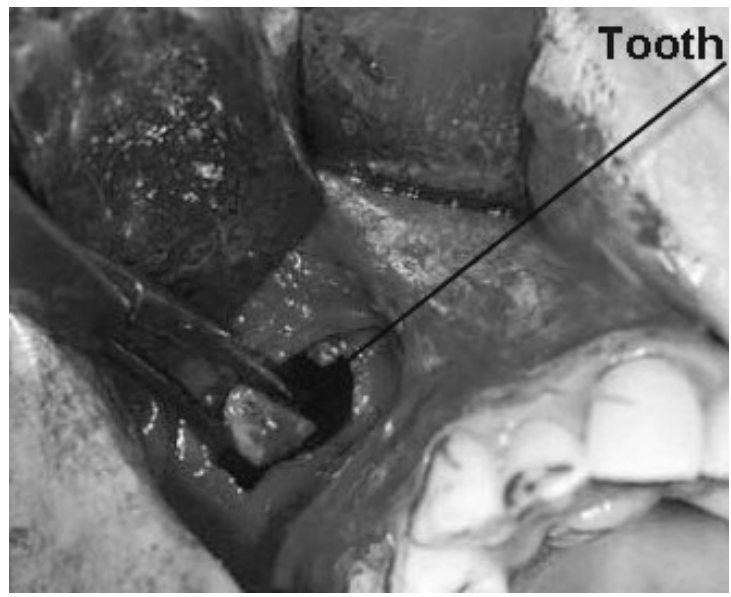

Figure 5: Removal of the displaced tooth through the bone Fenestration, by curved forceps.

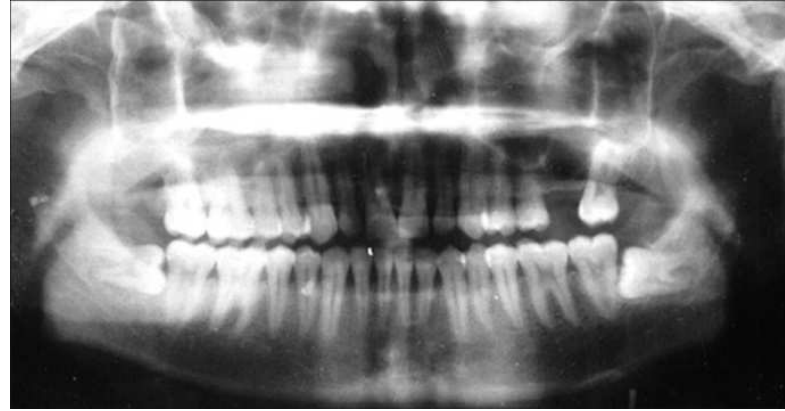

Figure 2: Panoramic radiograph taken after removal of the third molars, showing no evidence of tooth into the sinus

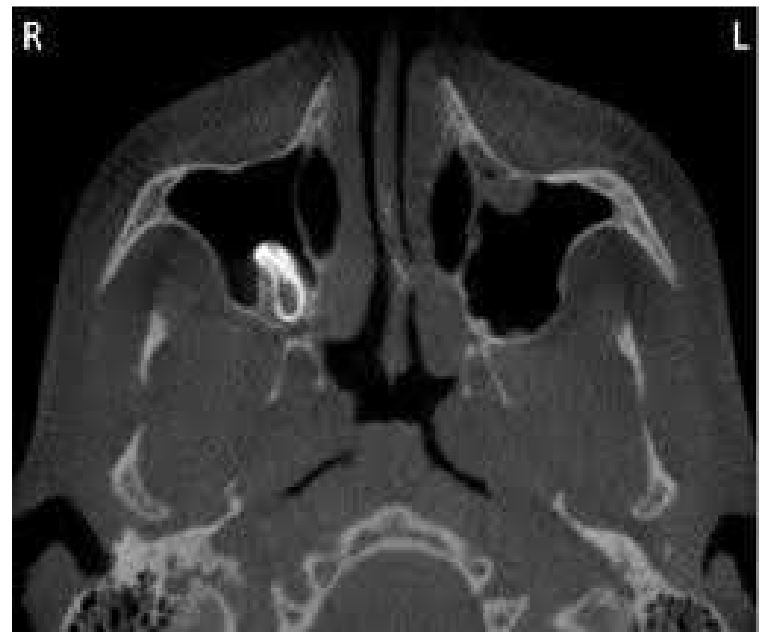

Figure 4:Transverse CT scan showing the anteroposition of the tooth inside the maxillary sinus. 


\section{Discussion}

Surgical removal of impacted maxillary third molars is a common procedure routinely carried out in dental offices. Most of these oral surgeries have an orthodontic indication as in the case reported in this paper, so as to prevent anterior tooth crowding after the orthodontic treatment is completed [3-5]. The decision to extract an impacted tooth must be based on careful weighing of potential benefits and risk [3]. It is important to confirm the indication and choose the most appropriatetime for surgery. A clear understanding of the development and movement of the specific third molar is essential for the decision-making process [3]. When the roots of a maxillary third molar are only one-half formed, surgery is less difficult to perform because in most cases the patient is less than 20 years old and the tooth is located in a more inferior position.

Surgical removal of impacted third molars is associated with moderate incidence of complications (around 10\%) [6]. However, less experienced surgeons are naturally expected to have significantly higher incidence of complications than trained, experienced surgeons [4]. Among the pre and postoperativecomplications associated with maxillary third molar extraction, the most commonly mentioned in literature are fractures of the maxillary tuberosity and accidental displacements into the infratemporal fossa or maxillary sinus [1]. Excessive apical force during use of elevators and incorrect surgical technique are quoted as the most common causes of these accidents. Although frequently mentioned, displacement of impacted maxillary third molar is rarely documented in literature[1,2]

In spite of correct preoperative management, including review of past medical history and clinical-radiographic examination, even experienced surgeons may face intra operative accident [6]. In this case, the patient should have promptly been informed about the accident and the possible treatment options should have been fully discussed.

In cases of accidental tooth displacement into the maxillary sinus, the most accepted treatment is the removal of the dislodged tooth to prevent future infections [2], preferably during the same surgical procedure. However, delayed treatment does not always precipitate immediate active sinus disease and sometimes the quiescent asymptomatic interval last several months before an acute infection develops [5]. Fortunately in this case the patient presented within a short interval of time.

Surgeons performing third molar surgery must not only be skilled and well trained, but also be able to decide whether asymptomatic impacted teeth need to be extracted [6] and which should be the most appropriate patient management in case of complications. Moreover, dental professionals can be faced with medico-legal problems. It is thus of paramount importance to keep all case records, including signed informed consent, x-ray films and others items, as well as to inform the patient immediately about any intraoperative accident taking place during exodontia and discuss which process will be followed to solve the unexpected situation.

\section{Conclusion}

Surgical removal of impacted maxillary third molars is a common procedure routinely carried out in dental offices. It is thus of paramount importance to keep all case records, including signed informed consent, x-ray films and others items, as well as to inform the patient immediately about any intraoperative accident taking place during exodontias.

\section{Funding: Nil, Conflict of interest: Nil, Permission from IRB: Yes}

\section{References}

1. Oberman M, Horowitz I, Ramon Y. Accidental displacement of impacted maxillary third molars. Int $\mathbf{J}$ Oral Maxillofac Surg. 1986 Dec;15(6):756-8.

2. Patel M, Down K. Patel M,Down K. Accidental displacement of impacted maxillary third molars. Br Dent J. 1994 Jul 23;177(2):57-9

3. Peterson LJ, Indresano AT, Marciani RD, Roser SM. Oral and Maxillofacial Surgery. Philadelphia: JB Lippincott Company; 1992.

4, Mercier P, Precious D. Risks and benefits of removal of impacted third molars.A critical review of the literature.Int J OralMaxillofac Surg. 1992 Feb;21(1):1727 
5. Stephens RG, Kogon SL, Reid JA. The unerupted or impactedthird molar-a critical appraisal of its pathologic potential.J Can Dent Assoc. 1989 Mar;55(3):201-7.
6. Nordenram A. Postoperative complications in oral surgery.Swed Dent J. 1983;7(3):109-14.

\section{How to cite this article?}

Zuhaib M, Sharma P, Doley B. Accidental displacement of impacted maxillarythird molar: A case report. Int J Med Res Rev 2015;3(7):757-760. doi: 10.17511/ijmrr.2015.i7.146. 